\title{
LmrR-mediated gene regulation of multidrug resistance in Lactococcus lactis
}

\author{
Herfita Agustiandari, ${ }^{1}$ Eveline Peeters, ${ }^{2}$ Janny G. de Wit, ${ }^{1}$ Daniel Charlier ${ }^{2}$ \\ and Arnold J. M. Driessen ${ }^{1}$
}

Correspondence

Arnold J. M. Driessen

a.j.m.driessen@rug.nl

Received 6 January 2011

Revised 13 February 2011

Accepted 14 February 2011

\author{
${ }^{1}$ Department of Microbiology, Groningen Biomolecular Sciences and Biotechnology Institute and \\ The Kluyver Centre for the Genomics of Industrial Fermentation, University of Groningen, \\ Nijenborgh 7, 9747 AG Groningen, The Netherlands \\ ${ }^{2}$ Erfelijkheidsleer en Microbiologie, Vrije Universiteit Brussel (VUB), Pleinlaan 2, B-1050 Brussels, \\ Belgium
}

\begin{abstract}
Multidrug resistance (MDR) in Lactococcus lactis is due to the expression of the membrane ATP-binding cassette (ABC) transporter LmrCD. In the absence of drugs, the transcriptional regulator $\mathrm{LmrR}$ prevents expression of the ImrCD operon by binding to its operator site. Through an autoregulatory mechanism LmrR also suppresses its own expression. Although the ImrR and ImrCD genes have their own promoters, primer extension analysis showed the presence of a long transcript spanning the entire $I m r R-I m r C D$ cluster, in addition to various shorter transcripts harbouring the ImrCD genes only. 'In-gel' Cu-phenanthroline footprinting analysis indicated an extensive interaction between $\mathrm{LmrR}$ and the $I m r R$ promoter/operator region. Atomic force microscopy imaging of the binding of $L m r R$ to the control region of ImrR DNA showed severe deformations indicative of DNA wrapping and looping, while LmrR binding to a fragment containing the ImrCD control region induced DNA bending. The results further suggest a drugdependent regulation mechanism in which the $I m r C D$ genes are co-transcribed with $I m r R$ as a polycistronic messenger. This leads to an LmrR-mediated regulation of $/ m r C D$ expression that is exerted from two different locations and by distinct regulatory mechanisms.
\end{abstract}

\section{INTRODUCTION}

In their natural environment, bacteria have to cope with naturally occurring toxic molecules (plant alkaloids, bile salts), harmful metabolic end-products, antimicrobial peptides, and secondary metabolites such as antibiotics. A widespread mechanism to counteract the inhibitory action of such molecules is their secretion from the cell by membrane-bound multidrug resistance (MDR) transporters (Chopra \& Roberts, 2001; Neyfakh et al., 1991; Tennent et al., 1985). For instance, the cationic berberine alkaloids produced by many plants are substrates for MDR pumps, such as QacA and NorA of Staphylococcus aureus (Hsieh et al., 1998; Neyfakh et al., 1993; Ng et al., 1994; Schumacher \& Brennan, 2003). Soil- or plant-associated organisms display the highest abundance of chromosomally encoded MDR efflux systems (Paulsen et al., 2000; Saier et al., 1998). MDR transporters are often subject to

Abbreviations: ABC, ATP-binding cassette; AFM, atomic force microscopy; EMSA, electrophoretic mobility shift assay; IR, inverted repeat; MDR, multidrug resistance; OP-Cu, Cu-phenanthroline; $\mathrm{P} /$, promoter/ operator; qPCR, quantitative PCR.

A supplementary figure and three supplementary tables are available with the online version of this paper. regulatory control (Grkovic et al., 2002), as their expression at a high level may be critical to cells (Eckert \& Beck, 1989; Gury et al., 2004). The expression of most MDR transporters is either positively or negatively controlled by local regulatory proteins (Eckert \& Beck, 1989; Hickman et al., 1990) and/or globally by stress-related regulators. For example, the overexpression of the acr $A B$ MDR locus in Escherichia coli is regulated by the global regulators MarA, Rob and SoxS, the local repressor AcrR (Alekshun \& Levy, 1997; Ma et al., 1996), and the quorum sensor regulator SdiA (Rahmati et al., 2002).

The Gram-positive bacterium Lactococcus lactis plays a major role in fermented dairy food production. L. lactis readily develops an MDR phenotype upon long-term exposure to structurally unrelated compounds such as daunomycin, Hoechst 33342, ethidium bromide, rhodamine 6G and cholate (Bolhuis et al., 1994; Lubelski et al., 2004; Mazurkiewicz et al., 2004). This MDR phenotype is due to the constitutive expression of the $\operatorname{lmr} C D$ genes, which encode a heterodimeric ATP-binding cassette (ABC) MDR transporter that secretes these compounds from the cell (Lubelski et al., 2006). Expression of the $\operatorname{lmrCD}$ genes is controlled by a local transcriptional regulator termed LmrR (Agustiandari et al., 2008). LmrR acts as a drug-sensitive 
repressor of the expression of the $\operatorname{lmr} C D$ genes. Most of the transcriptional regulators involved in MDR belong to the AraC, MarR, MerR and TetR families of transcriptional regulators. However, LmrR belongs to PadR, a family of mostly poorly characterized regulatory proteins that are involved in the regulation of detoxification mechanisms such as phenolic acid metabolism (Gasson et al., 1998; Overhage et al., 1999; Segura et al., 1999). Apart from LmrR, LadR from Listeria monocytogenes is the only characterized member of the MDR-related PadR regulators (Agustiandari et al., 2008; Huillet et al., 2006). In this family of regulators, the expression of the detoxification genes is typically induced by the presence of the toxic compounds in the medium via a direct interaction with the PadR-like regulator. Indeed, LmrR has been shown to bind several of the LmrCD substrates, such as Hoechst 33342, daunomycin and sodium cholate. On the other hand, LmrR does not bind $\rho$-coumaric acid and ferulic acid (our unpublished data), which are the phenolic acid derivatives that have been shown to bind to PadR (Gury et al., 2004). We have solved the structure of the LmrR dimer in the apo form and in two drug-bound forms, i.e. with Hoechst 33342 and daunomycin (Madoori et al., 2009). The dimer contains two N-terminal DNA-binding domains with a typical winged helix-turn-helix (wHTH) motif, while the C-terminal regions form a large flat central pore at the subunit interface. The latter constitutes the drug-binding pocket of LmrR, which is symmetrical with equal contributions from both monomers to the overall structure. On the other hand, the exact induction mechanism of LmrR will only be determined when the crystal structure of LmrR bound to DNA is available. However, one possible mechanism of $l m r R$ upregulation in the cell is via allosteric coupling between the drug- and DNA-binding sites, based on the comparison of different LmrR structures and the study of mutational analysis. The binding of the drug molecule to LmrR locks the dimer conformation in such a way that the DNA recognition helices fail to bind to their recognition site on the DNA major grooves (Madoori et al., 2009).

The $\operatorname{lm} r R$ gene is located upstream of the $\operatorname{lmr} C D$ genes (Agustiandari et al., 2008). In independently isolated drugresistant strains of L. lactis that are cross-resistant against a series of drugs, the $\operatorname{lmr} C D$ genes are constitutively expressed because of the presence of defective forms of LmrR that are no longer able to bind to the promoter/operator $(\mathrm{P} / \mathrm{o})$ region of the $\operatorname{lmrCD}$ genes (Lubelski et al., 2006). In these strains, the $\operatorname{lmrR}$ gene is also upregulated, suggesting that in wildtype cells, LmrR represses its own expression. Biochemical data demonstrate that LmrR indeed binds to its own promoter region (Agustiandari et al., 2008). Here, we have analysed the interaction between LmrR and the control regions of the $\operatorname{lmr} C D$ and $\operatorname{lm} r R$ genes using 'in-gel' $\mathrm{Cu}-$ phenanthroline (OP-Cu) footprinting analysis and atomic force microscopy (AFM) imaging. The data suggest distinct modes of binding of LmrR to the $l m r R$ and $l m r C D$ control regions, resulting in the formation of different transcripts that encode the structural genes either with or without the $\operatorname{lm} r R$ transcriptional regulator gene. Expression of both $\operatorname{lm} r R$ and $\operatorname{lmrCD}$ is elevated when cells are grown in the presence of drugs, suggesting a mechanism in which the regulator gene and the functional genes are induced and cotranscribed from a polycistronic messenger.

\section{METHODS}

Protein purification. Strep-tagged LmrR protein was overexpressed in L. lactis NZ9000, and purified by strep-tag affinity chromatography followed by chromatography with a heparin column, as described previously (Agustiandari et al., 2008).

Primer extension and RT-PCR analysis. RNA was extracted from L. lactis MG1363 using TRIzol reagent (Invitrogen). To prevent genomic DNA contamination, RNA samples were treated on-column with DNase I using an RNeasy Mini kit (Qiagen). Genomic DNA was extracted from L. lactis MG1363 using the GenElute Bacterial Genomic DNA kit (Sigma-Aldrich). Primer extension analysis was performed as described previously (Enoru-Eta et al., 2002) using AMV Reverse Transcriptase (Roche Applied Science). The 5' endlabelled primers DC620r or DC621r were used for transcription start determination of $l m r R$ or $\operatorname{lm} r C$, respectively. Labelling was done using $\left[\gamma^{32}\right]$ P-ATP (GE Healthcare). Reference ladders were generated by chemical sequencing methods (Maxam \& Gilbert, 1980). cDNA was prepared from about $2 \mu \mathrm{g} \mathrm{L}$. lactis RNA by using Superscript II Reverse Transcriptase (Invitrogen) and $200 \mathrm{ng}$ random primers. This reaction was followed by RNase $\mathrm{H}$ treatment (Fermentas). Transcript analysis was done by PCR with primers Cdprmf/DC621r or DC636f/ DC621r, using cDNA as template. Primer sequences are shown in Supplementary Table S1.

Electrophoretic mobility shift assays (EMSAs) and in-gel OP-Cu footprinting. Labelled DNA fragments were produced by PCR (ReadyMix Taq PCR Reaction Mix, Sigma-Aldrich) using a pair of primers, of which one was $5^{\prime}$ end-labelled with $\left[\gamma-{ }^{32} \mathrm{P}\right] \mathrm{ATP}$ (GE Healthcare). For the promoter regions of $\operatorname{lm} r R$ and $\operatorname{lm} r C D$, the primer pairs DC634f/DC620r and DC635f/DC621r, respectively, were used with L. lactis MG1363 genomic DNA as template. Labelled fragments were purified by PAGE. The truncated fragments of the promoter regions of $\operatorname{lmrR}$ and $\operatorname{lm} r C D$ were prepared similarly using the set of primers listed in Supplementary Table S2. EMSAs were performed as described previously (Enoru-Eta et al., 2000). Binding reactions were performed in LmrR binding buffer $(20 \mathrm{mM}$ Tris, $\mathrm{pH}$ 8.0, $1 \mathrm{mM}$ $\mathrm{MgCl}_{2}, 20 \mathrm{mM} \mathrm{KCl}, 0.1 \mathrm{mM}$ DTT, $0.4 \mathrm{mM} \mathrm{EDTA}, 12.5 \%, \mathrm{v} / \mathrm{v}$, glycerol) by incubating at $37{ }^{\circ} \mathrm{C}$ for $30 \mathrm{~min}$ in the presence of $25 \mu \mathrm{g}$ $\mathrm{ml}^{-1}$ sonicated herring sperm DNA as a non-specific competitor. $K_{\mathrm{D}}$ values were estimated based on these EMSAs, as the protein concentration at which about $50 \%$ of the DNA was bound (expressed in dimer equivalents). In-gel OP-Cu footprinting was performed as described previously (Peeters et al., 2004). Reference ladders were generated by chemical sequencing methods (Maxam \& Gilbert, 1980).

AFM. For AFM experiments, the DNA fragments were prepared by PCR with ReadyMix Taq PCR Reaction Mix (Sigma-Aldrich). The $\mathrm{P} / \mathrm{o}$ region of $l m r R$ was amplified as a $997 \mathrm{bp}$ fragment with the primer pair AFM lmrR pmtr FW/AFM lmrR pmtr RV, and L. lactis MG1363 genomic DNA as template. A 1016 bp fragment containing the $\mathrm{P} / \mathrm{o}$ region of $\operatorname{lm} r C D$ was amplified with the primer pair AFM $\operatorname{lm} r C D$ pmtr FW/AFM $\operatorname{lm} r C D$ pmtr RV. Following PCR amplification, all fragments were purified by agarose gel electrophoresis using a GenElute Gel Extraction kit (Sigma-Aldrich). A number of trials were performed to find the best concentration for both DNA and LmrR, with final concentrations of 1.86 and $0.04 \mu \mathrm{M}$ for $\operatorname{lm} r R$ DNA and LmrR 
protein, respectively; and 0.16 and $0.018 \mu \mathrm{M}$ for $\operatorname{lm} r C D$ DNA and LmrR protein, respectively. These binding reactions were diluted in LmrR binding buffer in a total volume of $15 \mu \mathrm{l}$. The mixture was then diluted twofold in adsorption buffer (40 mM HEPES, pH 6.9, $10 \mathrm{mM}$ $\mathrm{NiCl}_{2}$ ), and $15 \mu \mathrm{l}$ of the suspension was deposited on freshly cleaved mica. This was incubated for $5 \mathrm{~min}$ to allow adsorption of the nucleoprotein complexes. Subsequently, samples were rinsed with deionized ultrapure water and excess water was blotted off with absorbent paper. The mica surface was blown dry in a stream of filtered air. A NanoScope IIIa atomic force microscope (Digital Instruments/ Veeco) was operated in the tapping mode, in air. Images of $512 \times 512$ pixels were acquired by using Nanoprobe scanning probe microscopy (SPM) tips, type RTESP7 (Veeco) with a 115-135 $\mu \mathrm{m}$ cantilever, a nominal spring constant of $50 \mathrm{~N} \mathrm{~m}^{-1}$ and resonance frequencies in the range from 244 to $295 \mathrm{kHz}$. The scan size was $1.5 \mu \mathrm{m} \times 1.5 \mu \mathrm{m}$ and the scan rate was $2 \mathrm{~Hz}$. NanoScope 6.11r1 software (Digital Instruments/ Veeco) was used to flatten the images and to make zoomed 3D surface plots. The contour lengths of DNA molecules or DNA arms of complexes were measured by manual tracing with ImageJ (Abramoff et al., 2004). DNA molecules or complexes with overlapping parts or with visible anomalies were omitted from the analysis.

Quantitative PCR (qPCR). Cultures of L. lactis NZ9000 and NZ9000( $\Delta l m r R)$ (Agustiandari et al., 2008) were grown overnight on M17 supplemented with $0.5 \%$ glucose at $30{ }^{\circ} \mathrm{C}$. Cultures were diluted $1: 100$ to an $\mathrm{OD}_{660}$ of $0.07-0.08$ in the same medium with or without $1 \mu \mathrm{M}$ Hoechst 33342 (Sigma-Aldrich) or $20 \mu \mathrm{M}$ daunomycin (Calbiochem - VWR). These subinhibitory drug concentrations ensured near-identical growth rates of the different types of cells. Cells were further grown at $30{ }^{\circ} \mathrm{C}$, and during the early exponential, late exponential and stationary growth phases, samples of $5 \mathrm{ml}$ were collected and flash-frozen in liquid nitrogen. Total RNA was isolated using TRIzol reagent (Zaidi et al., 2008). Residual chromosomal DNA was removed by using the TURBO DNA-free kit (Ambion, Applied Biosystems) according to the manufacturer's instructions. Purified RNA was quantified by measuring $A_{260}$ using a NanoDrop ND1000 spectrophotometer. The quality of the RNA preparations was checked by visualizing the integrity of $16 \mathrm{~S}$ and $23 \mathrm{~S}$ rRNA on an agarose gel, and by verifying the absence of DNA contamination by PCR. The cDNA molecules were synthesized using an iScript cDNA synthesis kit (Bio-Rad) as recommended by the manufacturer. Total RNA was isolated from at least two separately grown replicate cultures.

For the qPCR experiments, the primers were designed to have a length of 22-23 nt, a G/C content of 45-47\% (see Supplementary Table S3) and a $T_{\mathrm{m}}$ of about $60-65^{\circ} \mathrm{C}$. The lengths of the primer products ranged between 200 and 230 bp. qPCR was carried out on a MiniOpticon Real-Time PCR system (Bio-Rad). After dilution of the cDNA, $4 \mu$ was added to $21 \mu \mathrm{l}$ of the PCR mixture $(12.5 \mu \mathrm{l}$ iQ SYBR Green Supermix and $0.5 \mu \mathrm{l}$ of each primer at $\left.10 \mathrm{pmol} \mu \mathrm{l}^{-1}\right)$. Thermal cycling conditions were as follows: initial denaturation at $95{ }^{\circ} \mathrm{C}$ for $3 \mathrm{~min}$, followed by 40 cycles of $95{ }^{\circ} \mathrm{C}$ for $20 \mathrm{~s}, 55^{\circ} \mathrm{C}$ for $20 \mathrm{~s}$ and $72{ }^{\circ} \mathrm{C}$ for $30 \mathrm{~s}$. An additional step starting from 65 to $95{ }^{\circ} \mathrm{C}$ was performed to establish a melting curve. This was used to verify the specificity of the PCR for each primer set. qPCR measurements were performed in duplicate for each sample. The tufA gene was used as an internal control and for normalization of the results (Friedrich \& Lenke, 2006).

\section{RESULTS}

\section{Mapping of the transcription start sites of ImrCD and $I m r R$}

Primer extension analysis was performed to map the transcription initiation sites of the $\operatorname{lm} r C D$ and $l m r R$ genes using RNA extracted from L. lactis MG1363 cells (Fig. 1). Transcription of $\operatorname{lmr} R$ is initiated at a single $G$ residue located $26 \mathrm{nt}$ upstream of the ATG start codon (Figs 1a and $2 \mathrm{a}$ ). In contrast, $\operatorname{lm} r C D$-specific reverse transcription resulted in at least four different cDNA molecules (Figs $1 \mathrm{~b}$ and $2 \mathrm{~b}$ ). Transcripts $\mathrm{C}$ and $\mathrm{D}$ start at an A residue 55 and $61 \mathrm{nt}$ upstream of the ATG start codon of $\operatorname{lmr} C$, respectively. Transcript $\mathrm{B}$ starts at a $\mathrm{T}$ residue that is located 100 bp upstream of the ATG start codon of LmrC. A fourth cDNA molecule represents a transcript that is larger than the labelled fragment used for the MaxamGilbert sequencing ladder, which was prepared by PCR amplification using primers CDprmf and DC621r (Fig. 1d, Supplementary Table S1). Therefore, this transcript must also contain at least part of the ORF of $\operatorname{lmr} R$. To test whether or not this transcript corresponded to transcript A as detected by $\operatorname{lm} r R$-specific primer extension, RT-PCR analysis was performed using primer pairs CDprmf/ DC621r and DC636f/DC621r (Fig. 1c, d). These reactions resulted in amplification, confirming the existence of an mRNA molecule that spans both the $\operatorname{lm} r R$ gene and the $\operatorname{lm} r C D$ gene. It thus appears that an RNA polymerase initiated at the $l m r R$ promoter may proceed till the end of $\operatorname{lm} r D$. Indeed, using the program TransTerm, intrinsic terminators were predicted to occur neither in the $\operatorname{lmr} R$ and $\operatorname{lmr} C D$ genes nor in the intergenic region between $\operatorname{lm} r R$ and $\operatorname{lm} r C$, although a terminator was detected downstream of $\operatorname{lmrD}$. Putative Shine-Dalgarno (SD) sequences for both $\operatorname{lmrR}$ and $\operatorname{lmr} C$ were detected between the seventh base and the twelfth base upstream of the respective start codons. Regions that showed sequence conservation with the consensus -35 and -10 promoter elements could be identified slightly upstream of the start of transcripts A and B (Fig. 2a, b). Both promoters showed a putative Pribnow box with a perfect match to the consensus and a -35 sequence with a good match, the two being separated by a linker of ideal length (17 bp). However, in view of the multiple transcripts observed for $\operatorname{lm} r C D$, additional promoter element(s) might be involved in $\operatorname{lm} r C D$ expression, although it cannot be excluded that these transcripts may arise by degradation of the longer transcripts.

\section{Identification of the LmrR-binding sites in the control regions of $I m r R$ and $I m r C D$}

Previously, it has been shown that LmrR protects a long stretch of DNA in the control region of its own gene against DNase I (Agustiandari et al., 2008). Here, we show that LmrR forms multiple complexes with ${ }^{\mathrm{P}} \% \operatorname{lm} r R$ DNA as observed in an EMSA (Fig. 3a). This result suggests the presence of multiple binding sites that likely involve several copies of LmrR. Three complexes (B1, B2 and B3) showed a slightly different migration velocity, whereas complex B4, which was detected only at the highest LmrR concentration used $(0.8 \mu \mathrm{M})$, was strongly retarded in its mobility. The average apparent binding dissociation constant $\left(K_{\mathrm{D}}\right)$ of the LmrR- $\mathrm{P} / \mathrm{o} l m r R$ interaction was around $30 \mathrm{nM}$. There was a 
(a)

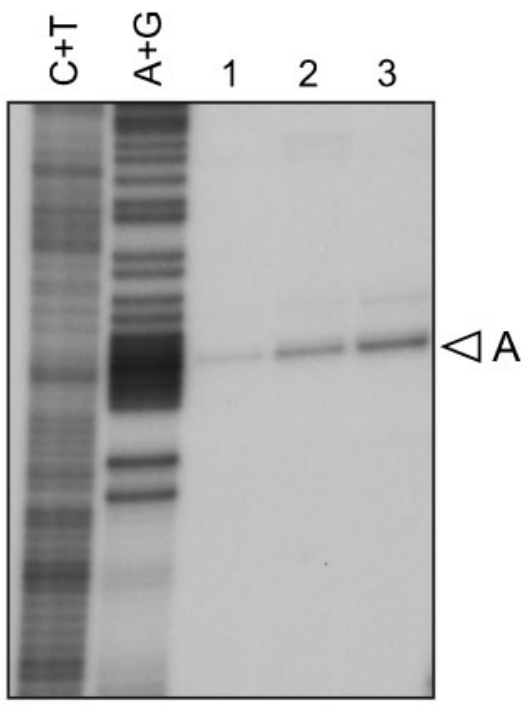

(c)

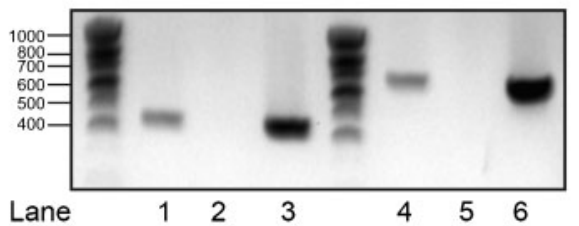

(b)

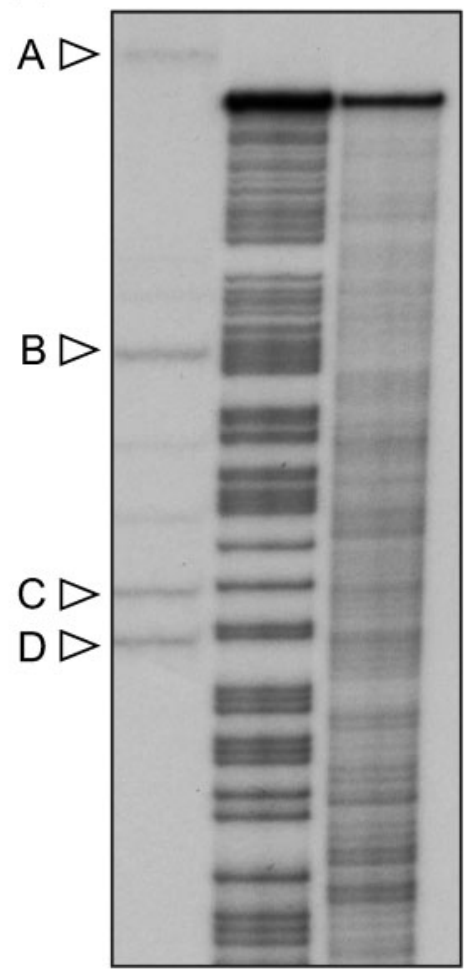

(d)

$\begin{array}{llll}0 \quad 500 & 1000 & 1500 & 200\end{array}$
2000 2500 3000 3500 4000 4500

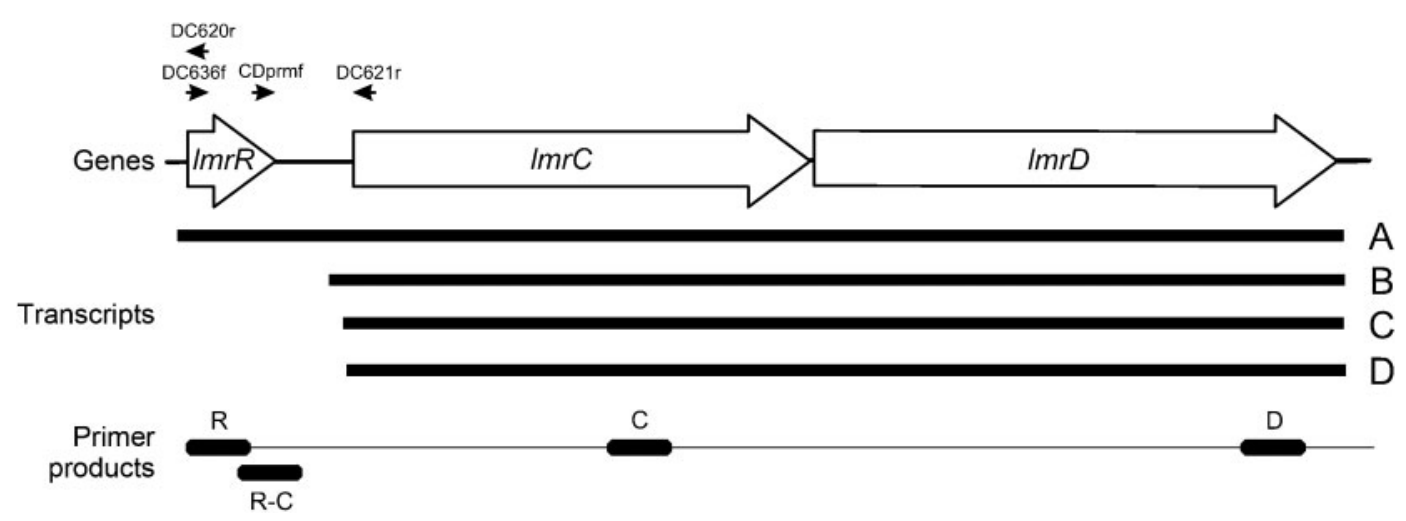

Fig. 1. Primer extension analyses of transcripts showing the transcription start sites of (a) ImrR using primer DC620r and (b) ImrC using primer DC621r. The amounts of total RNA used were $12.5 \mu \mathrm{g}$ (lane 1), $25 \mu \mathrm{g}$ (lane 2), $50 \mu \mathrm{g}$ (lane 3) and $100 \mu \mathrm{g}$ (lane 4). The main primer extension products are indicated with arrowheads and are designated $A$ to $D . A+G$ and $C+T$ represent the corresponding Maxam-Gilbert sequencing ladders. A systematic correction in the alignment of the cDNA product with the sequencing ladders has been performed to take into account the difference in migration velocity of the cDNA and the reference ladders due to different ends generated by the AMV reverse transcriptase and the chemical modification and cleavage reactions. (c) RT-PCR analysis with cDNA as template with primers CDprmf and DC621r (lane 1); as lane 1, without addition of reverse transcriptase (negative control) (lane 2); with primers CDprmf and DC621r and with genomic DNA as template (lane 3); with primers DC636f and DC621r and with CDNA as template (lane 4); as lane 4, but without addition of reverse transcriptase (negative control) (lane 5); with primers DC636f and DC621r and with genomic DNA as template (lane 6). (d) Schematic overview of the transcripts A, B, C and D with respect to the ORFs (indicated with open arrows) and primer products used for qPCR. The locations of the primers used for primer extension and RT-PCR analysis are also indicated. 
(a) $\mathrm{P} / \mathrm{Im} r R$

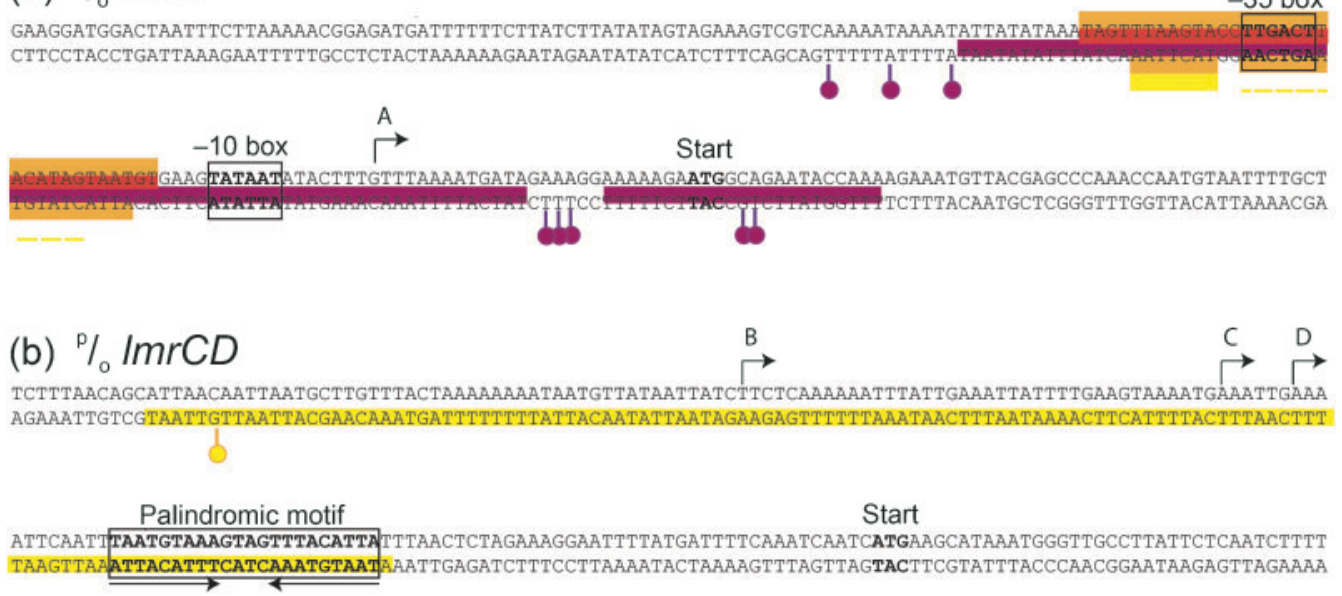

(c) $\mathrm{p} / \mathrm{o} / m r R$

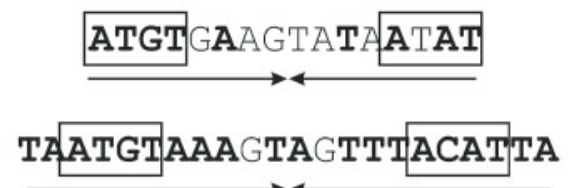

p/o ImrCD

PadR consensus

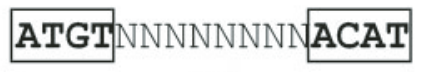

Fig. 2. Schematic representation of the transcriptional elements on (a) $I m r R$ and (b) $I m r C D$ control region DNA, including the positions of the -35 and -10 regions, the transcription initiation sites, and the translation start codon (bold type). For the promoter region of $\operatorname{lmrCD}$, the predicted promoter elements are only shown for transcript $\mathrm{B}$. The letters A to $\mathrm{D}$ represent the $5^{\prime}$ end of the major transcripts observed in primer extension analysis. In addition, the protected areas observed in the footprinting assays of $\mathrm{LmrR}$ binding to $\mathrm{P} / \mathrm{ImrR}(\mathrm{A})$ and $\mathrm{P} / \mathrm{ImrCD}(\mathrm{B})$ are shown. For $\mathrm{P} / \mathrm{ImrR}$, protection zones are indicated for the complexes B1 (yellow), B2 (orange), B3 (red) and B4 (purple). For $\mathrm{P} / \mathrm{ImrCD}$, the protection zone is indicated in yellow. The ball-and-stick symbols represent the positions of the hyper-reactivity sites. The identified imperfect palindromes are shown in the sequences with double arrows. (c) Representation of the imperfect IRs as identified in $\mathrm{P} / \mathrm{o} / m r R, \mathrm{P} / \mathrm{o} / m r C D$ and the PadR consensus IR. Palindromic residues are in bold type, and the conserved PadR motif is boxed.

rapid transition in the formation of the different complexes, which suggested cooperativity in the binding. EMSAs were also performed with truncated DNA fragments containing only a part of the $\operatorname{lmrR}$ control region or ORF (Fig. 3b, c). Interestingly, LmrR was able to bind DNA probes consisting of the control region alone (Rtruncl and Rtrunc2), and also a DNA probe consisting mainly of the lmrR gene, starting only 4 bp upstream of the transcription start (Fig. 3c) (Rtrunc3). However, although the Rtrunc2 and Rtrunc3 fragments were of nearly identical length, the LmrR-Rtrunc3 complex migrated differently and was less stable, indicative of a different architecture and/or stoichiometry of this complex. These binding events were specific, since no complex formation was observed under identical conditions with a DNA fragment corresponding to the region upstream of the -35 -promoter element of $\operatorname{lm} r \mathrm{C}$ (Supplementary Fig. S1).

To further determine which regions of the DNA are recognized by LmrR in each of the multiple complexes observed in the EMSA, in-gel OP-Cu footprinting was performed with the various complexes (Fig. 3d). A stretch of $6 \mathrm{nt}$ was clearly protected in the fastest-migrating complex B1 (Fig. 2a, yellow bar, and Fig. 3d). This initially protected site might be considered as a 'core'-binding binding site from which LmrR binding is nucleated. In addition, a difference in the cleavage pattern, between on the one hand the complexed $\mathrm{B} 1$ form and on the other hand the free I and $\mathrm{F}$ forms, could be observed in an approximately $13 \mathrm{nt}$ long region, immediately downstream of this stretch (Fig. 2a, yellow dashed bar, and Fig. 3d). This stretch, including the -35 box, is part of a region that is much more clearly protected in complexes B2 and B3 (Fig. $2 \mathrm{a}$, orange and red bars). Footprinting with a DNA fragment with the top strand labelled revealed no clearcut differences in the protected regions of complexes B2 and B3. This might be explained by (i) a slightly different architecture of the complex, (ii) a different stoichiometry of the complex without supplementary DNA contacts, or (iii) the formation of a 'sandwich-like' structure containing two DNA molecules. The highly retarded complex B4 showed extensive protection encompassing about $102 \mathrm{bp}$, 
(a)

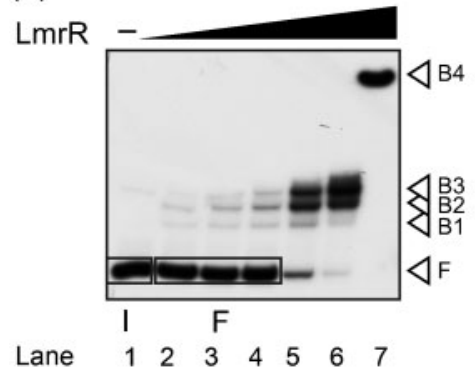

(b)

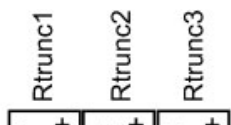

LmrR

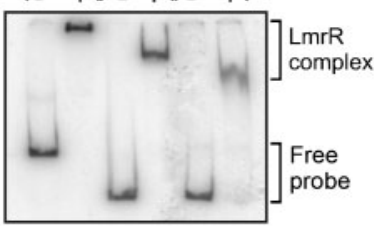

(c)

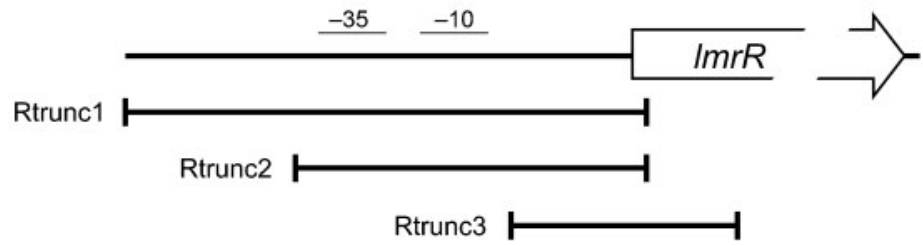

(d)

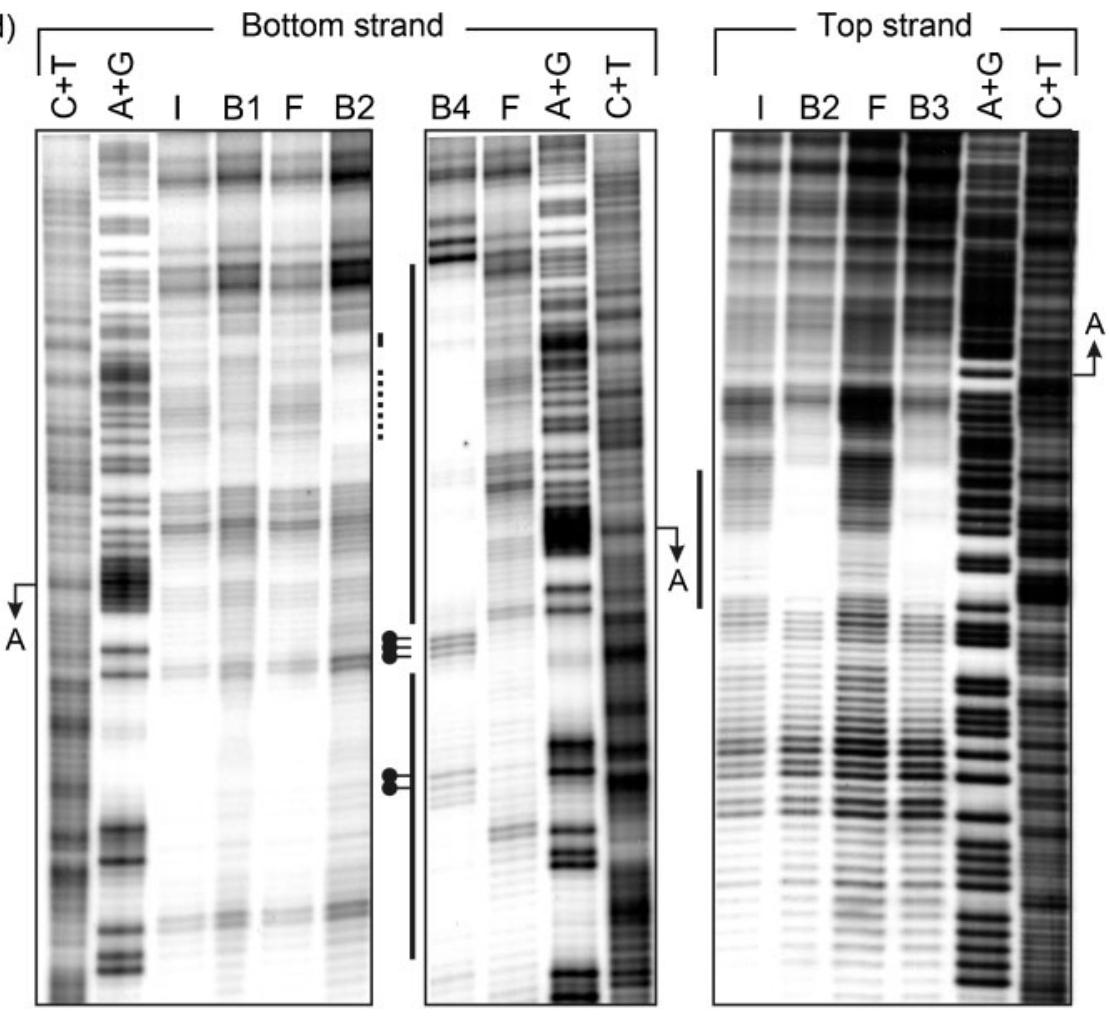

Fig. 3. Binding of $L m r R$ to the $/ m r R \%$ region. (a) EMSA of the binding of purified $L m r R$ to a 210 bp labelled DNA fragment containing the $I m r R P$ o region. The $\mathrm{LmrR}$ stock concentration was $81.5 \mu \mathrm{M}$ (dimer) and was further diluted. No LmrR was added in lane 1, and LmrR was added at concentrations of $0.01 \mu \mathrm{M}$ (lane 2), $0.02 \mu \mathrm{M}$ (lane 3), $0.03 \mu \mathrm{M}$ (lane 4), $0.1 \mu \mathrm{M}$ (lane 5), $0.2 \mu \mathrm{M}$ (lane 6) and $0.8 \mu \mathrm{M}$ (lane 7). The positions of the free DNA (F) and of the different LmrR-bound DNA complexes (B1, B2, B3 and B4) are indicated. These different complexes and the boxes named I (input DNA) and F (free DNA) were excised for in-gel footprinting analysis. (b) EMSA of the binding of purified LmrR to truncated DNA fragments Rtrunc1 (266 bp), Rtrunc2 (170 bp) and Rtrunc3 (152 bp), corresponding to the regions of the ImrR operator site indicated in Fig. 2. LmrR was added at a final concentration of $1.85 \mu \mathrm{M}$ (dimer). (c) Schematic of the coverage of the $\mathrm{P} / \mathrm{o} / m r R$ truncated fragments Rtrunc1, Rtrunc2 and Rtrunc3 relative to the $I m r R$ promoter elements and ORF. (d) In-gel OP-Cu footprinting of LmrR binding to the $\mathrm{P} /$ region of $I m r R$ with the bottom strand labelled (left two panels) or with the top strand labelled (right panel). The EMSA that was used for the experiment with the bottom strand labelled is shown in Fig. 3(a). Next to each autoradiograph, protected regions are indicated with a vertical line. Hyper-reactivity sites are also indicated with ball-and-stick symbols. For the far-left panel, the full line 
corresponds to protection observed in complexes $\mathrm{B} 1$ and $\mathrm{B} 2$, whereas the dashed line corresponds to additional protection observed in complex B2 alone. $A+G$ and $C+T$ represent the Maxam-Gilbert sequencing ladders. Next to the ladder, the position of the transcription start is shown. A schematic representation of the protected regions is displayed in Fig. 2.

including the entire promoter and transcription start site (Fig. 2a, purple bar, and Fig. 3d). In this protected region, an imperfect inverted repeat (IR) is apparent (Fig. 2a, c). This IR exhibited one mismatch as compared with the PadR consensus sequence, but had the optimal spacing of $8 \mathrm{nt}$ between the palindromic half sites (Fig. 2c) (Huillet et al., 2006). Several hyper-reactivity signals were observed for complex B4, indicating local DNA deformations (minor groove widening) upon LmrR binding (Figs 2a and $3 \mathrm{~d}$ ).

The binding of LmrR to DNA fragments covering the $\mathrm{P} / \mathrm{o}$ region of the $\operatorname{lm} r C D$ genes showed a distinctively different signature. Previous footprinting results had indicated that LmrR binds to two different sites on the $\operatorname{lmr} C D$ promoter (Agustiandari et al., 2008): site I, comprising the -35 and -10 regions, and site II, which harbours an imperfect IR similar to the PadR consensus sequence but with a spacing of $10 \mathrm{bp}$ (Fig. 2c) (Huillet et al., 2006). EMSAs were performed with shortened probes corresponding to either site I or site II (Supplementary Fig. S1). It appeared that LmrR bound DNA probes containing the -35 and -10 regions (site I) more strongly than the probes containing site II with the palindromic sequence. With the full-length $\operatorname{lm} r C D \mathrm{p} \%$ DNA, a major specific complex was observed upon binding of LmrR (Fig. 4a). The overall binding affinity of this interaction appeared to be two- to fourfold lower than the affinity for $\mathrm{P} / \mathrm{o} \operatorname{lm} R$ DNA, with an apparent $K_{\mathrm{D}}$ of about $150 \mathrm{nM}$. In-gel OP-Cu footprinting of LmrR binding to the $\operatorname{lmrCD}$ control region showed a single extended protected region of about $126 \mathrm{bp}$ (Fig. 4b) that overlapped all the transcription initiation sites (site I) in the $\operatorname{lm} r C D$ control region and their cognate promoter elements, and the previously identified imperfect IR (site II; Fig. 2b). At the promoter-distal side of the protected region, a hyper-reactivity site was observed, again indicating LmrR-induced DNA deformations. These results demonstrate different modes of binding of LmrR to the $\operatorname{lm} r R$ and $\operatorname{lm} r C D \mathrm{P} / \mathrm{o}$ regions.

\section{AFM of the binding of LmrR to ImrR and ImrCD promoter DNA}

AFM was used to visualize the architecture of LmrR complexes formed with the $\mathrm{p} / \mathrm{o}$ regions of $\operatorname{lm} r \mathrm{R}$ and $\operatorname{lm} r C D$ (Figs $4 \mathrm{c}$ and 5). Tapping-mode AFM in air was used for high-resolution topographic imaging of the soft protein/ DNA sample surfaces without creating destructive frictional forces. With the $\operatorname{lmrR} \mathrm{p} / \mathrm{o}$ DNA, 22 unbound $997 \mathrm{bp}$ long DNA molecules and 41 DNA-LmrR complexes were analysed. The contour length of unbound DNA molecules was manually traced using ImageJ software, resulting in a mean contour length of $313 \mathrm{~nm}$ (SD $29 \mathrm{~nm}$; Fig. 5c). This yielded an axial basepair rise of $0.31 \mathrm{~nm} \mathrm{bp}{ }^{-1}$, which is slightly lower than the theoretical rise of B-form DNA (i.e. $0.34 \mathrm{~nm} \mathrm{bp}^{-1}$ ), but in good agreement with other AFM studies. This difference can be explained by the limited resolution of the microscope and the smoothing procedure that rounds sharp bends (Rivetti et al., 1996). Based on DNA persistence length analysis of other DNA molecules measured under similar experimental conditions, it can be assumed that the molecules are able to freely equilibrate on the surface before capture (Peeters et al., 2006; Minh et al., 2009).

A heterogeneous population of LmrR- $\operatorname{lm} r R$ nucleoprotein complexes was observed, ranging from having apparently a single site bound, possibly the 'core' nucleation site (Fig. 5 a, images 1-3), to having apparently two sites bound or even large complex regions. Here, several LmrR molecules seemed to be involved in the condensation of the binding site area (Fig. 4c, image 4). This type of complex most probably corresponds to the B4 population observed in the EMSA (Fig. 3a). It is clear that LmrR binding induces severe DNA deformations, including sharp DNA bending, DNA condensation and possibly even DNA wrapping around the protein (local constrained toroidal DNA supercoiling) or DNA looping (Fig. 5a). The contour length of the naked DNA arms of all complexes was measured without making a distinction between the different types of complexes (depending on the degree of binding; Fig. 5b). These measurements resulted in a mean length of $79 \mathrm{~nm}$ (SD $39 \mathrm{~nm}$ ) for the short DNA arm and $191 \mathrm{~nm}(\mathrm{SD} 40 \mathrm{~nm})$ for the long DNA arm. Therefore, the total mean visible contour length of the complexes (short + long arms) was $270 \mathrm{~nm}$ (SD $52 \mathrm{~nm}$; Fig. 5c). This is a difference of $43 \mathrm{~nm}$ from that of the mean length of the unbound DNA molecules, and taking a basepair rise of $0.31 \mathrm{~nm} \mathrm{bp}{ }^{-1}$ into account, this corresponds to about 139 bp condensed inside the DNA-LmrR complex. Due to the heterogeneity of the complexes, the distributions are broad. These observations demonstrate that the mechanism of binding of LmrR to the $\operatorname{lmrR} \mathrm{P} / \mathrm{o}$ DNA involves interactions with multiple LmrR molecules that are likely bound in a cooperative fashion. Furthermore, the extent of the condensation is in good agreement with the length of the protected region as observed for complex B4 in in-gel $\mathrm{OP}-\mathrm{Cu}$ footprinting.

AFM experiments with the $\operatorname{lmrCD}$ control region DNA resulted in LmrR-DNA complexes with a more homogeneous architecture than that of the $\mathrm{LmrR}-\mathrm{P} / \mathrm{o} \operatorname{lm} r R$ complexes (Fig. 4c). The results indicated that LmrR induces a significant DNA bending. Typically, the complexed region had a bilobed structure. The two 'blobs' present in the AFM images may represent the 
(a)

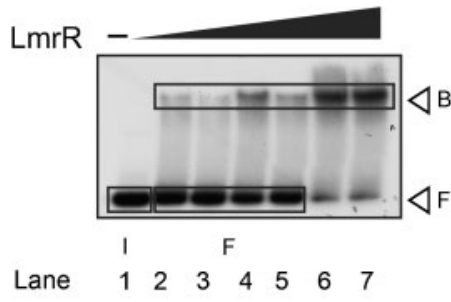

(c)

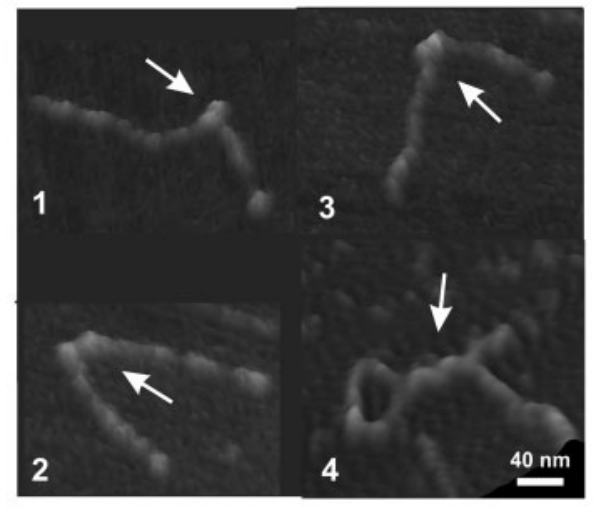

(b)

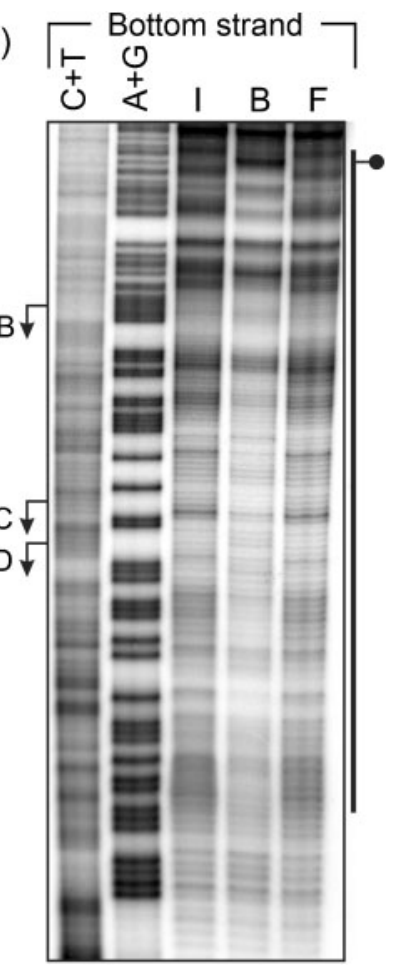

Fig. 4. Binding of $\mathrm{LmrR}$ to the $\operatorname{lmr} C D \mathrm{P} / \mathrm{o}$ region. (a) EMSA of the binding of $L m r R$ to a DNA fragment corresponding to the $I m r C D \%$ region. No LmrR was added in lane 1 , and $\mathrm{LmrR}$ was added at concentrations of $0.01 \mu \mathrm{M}$ (lane 2), $0.02 \mu \mathrm{M}$ (lane 3), $0.03 \mu \mathrm{M}$ (lane 4), $0.1 \mu \mathrm{M}$ (lane 5), $0.2 \mu \mathrm{M}$ (lane 6) and $0.8 \mu \mathrm{M}$ (lane 7). The positions of input (I), free DNA (F) and bound complexes (B) are indicated. (b) Ingel OP-Cu footprinting analysis of the $\mathrm{LmrR}-$ ImrCD promoter region complex that was excised from the gel shown in Fig. 3(b). Next to the autoradiograph, the protected regions are indicated with a vertical line and the hyperreactivity sites as a ball-and-stick symbol. $A+G$ and $C+T$ represent the MaxamGilbert sequencing ladders. Next to the ladder, the positions of the transcription starts are shown. A schematic representation of the protected region is displayed in Fig. 2. (c) A selection of AFM images of $\mathrm{LmrR}-{ }^{\mathrm{P}} \%$ / $/ m r C D$ protein-DNA complexes (indicated by the arrows), as typically observed. binding of two LmrR dimers to the DNA (Fig. 4c) (Madoori et al., 2009). Taken together, the AFM results support the notion that LmrR binds the $\operatorname{lmrR}$ and $\operatorname{lmrCD}$ operator regions by different mechanisms, and indicate higher-order interactions of LmrR with the operator region of its own gene.

\section{Expression analysis of the $I m r C D$ and $I m r R$ genes in L. lactis}

Our analysis indicated the presence of a long transcript harbouring both the $\operatorname{lmrR}$ gene and the $\operatorname{lmrCD}$ gene. To assess the expression levels of $l m r R$ in growing cell cultures, qPCR was employed on RNA extracted from L. lactis cells

(a)

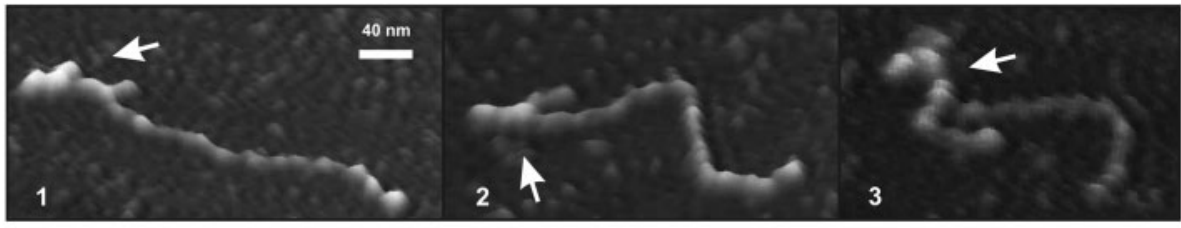

(b)

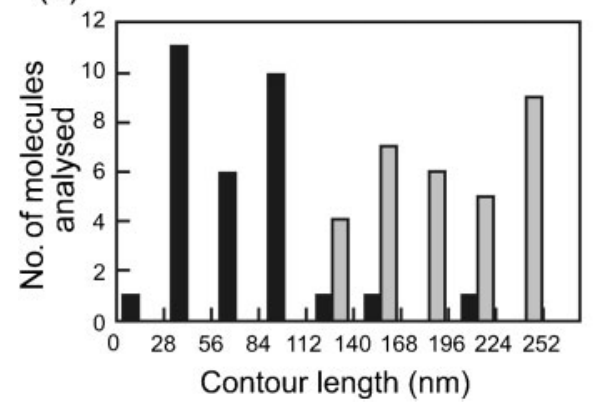

(c)

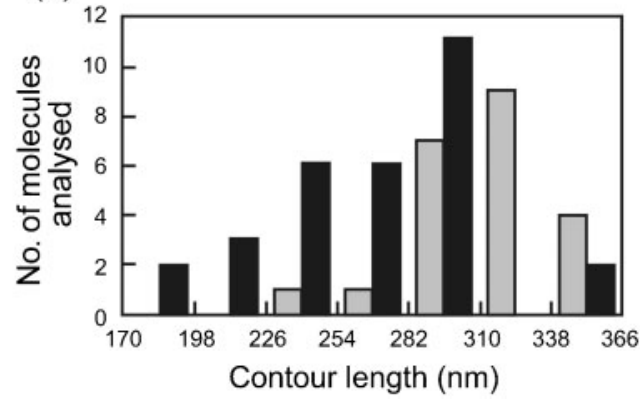

Fig. 5. AFM analysis of the binding of $\mathrm{LmrR}$ to the $\mathrm{P} / \mathrm{o}$ site of $I m r R$. (a) A selection of AFM images of LmrR-P $/ \mathrm{O} / \mathrm{mrR}$ proteinDNA complexes (indicated by the arrows). (b) Contour length measurements of the long (grey bars) and short (black bars) arms of LmrR complexed with the DNA fragment. (c) Contour lengths of the sum of the long and short arms of the LmrR-complexed DNA fragments (black bars) and of the free DNA fragments (grey bars). The $y$ axes indicate the number of analysed molecules. 
growing on M17 medium with glucose in the absence and presence of subinhibitory concentrations of the drugs daunomycin and Hoechst 33342. As a control, L. lactis NZ9000 $(\Delta l m r R)$ was used, which expresses the $l m r C D$ genes constitutively (Agustiandari et al., 2008). Primer sets were designed to monitor the transcript levels of $\operatorname{lmr} R$, $\operatorname{lm} r C$ and $\operatorname{lmrD}$ individually, and in addition, a set was designed that detected the intergenic region that separates the $\operatorname{lmrR}$ and $\operatorname{lmrCD}$ genes in the long polycistronic $\operatorname{lm} r R-$ $\operatorname{lmr} C D$ transcript (Fig. 1d). Expression levels were related to that of the housekeeping gene tufA, which encodes the translation elongation factor Tu (Friedrich \& Lenke, 2006). In addition, the $\sec Y$ transcript, encoding the major subunit of the preprotein translocase, was monitored. The expression level of these control genes was constant during exponential growth, but unlike tufA, the expression of $\sec Y$ dropped when cells entered the stationary phase (Fig. 6). As expected, the $\operatorname{lm} r C$ and $l m r D$ genes were highly expressed in L. lactis $\mathrm{NZ9000}(\Delta l m r R)$ cells during the exponential and stationary growth phases. With L. lactis NZ9000 wild-type cells, lower levels of $\operatorname{lmrCD}$ expression were observed that dropped dramatically when the cells entered the stationary phase. A similar response was observed with the transcript containing the $\operatorname{lm} r R$ gene and the $\operatorname{lm} r R-\operatorname{lm} r C$ intergenic region, suggesting that the long transcript is present during the entire exponential growth phase. When cells were exposed to daunomycin (Fig. 6) or Hoechst 33342 (data not shown), expression levels of $\operatorname{lmr} C$ and $\operatorname{lm} r D$ increased. Since Hoechst 33342 also caused an increase in tufA expression, the corresponding data could not be quantified. Remarkably, exposure to the drugs also resulted in increased levels of the transcript harbouring the $\operatorname{lm} r R$ gene and the $\operatorname{lm} r R-\operatorname{lm} r C$ intergenic region. Summarizing, these data demonstrate that both the regulatory $\operatorname{lm} r R$ gene and the structural $\operatorname{lm} r C D$ genes are expressed in exponentially growing wild-type cells and that their expression increases upon exposure to toxic drugs.

\section{DISCUSSION}

The ABC transporter LmrCD has previously been shown to be a major determinant of the MDR phenotype in L. lactis (Lubelski et al., 2006). Transcription of $\operatorname{lm} r C D$ is controlled by LmrR, a local regulatory repressor whose gene is located upstream of $\operatorname{lmr} C D$ (Agustiandari et al., 2008). The $\operatorname{lmrR}$ and $\operatorname{lmrCD}$ genes are transcribed in the same direction. LmrR has previously been shown to function as a drug-controlled negative transcriptional regulator of the expression of the $\operatorname{lm} r C D$ genes. Our current primer extension analysis now reveals the presence of three major transcripts of $\operatorname{lmrCD}$, and one longer transcript spanning the $\operatorname{lmrR}$ and $\operatorname{lmrCD}$ genes. The occurrence of multiple transcripts of $\operatorname{lmr} C D$ might indicate the presence of alternative promoters. Alternative promoters are quite frequent in bacteria and may be used to cope with changes in the environment, such as altered nutritional requirements that result in changes in the expression of a particular gene. In most cases, however, one promoter is responsible for constitutive expression, while the others are inducible by different stimuli (Musso et al., 1977) and may even function with another alternative sigma factor. At this stage it is unclear whether the presence of these multiple transcripts indeed reflects functional differences in the regulation and/or expression mechanism. Possibly, additional global or local regulators are involved in the regulation of the different promoters. However, qPCR analysis of the expression of $l m r R$ (from the long transcript) and of the $\operatorname{lmrCD}$ genes (likely both from the long and shorter transcripts) indicated that these genes are expressed throughout the exponential growth phase, and that their expression is further elevated when cells are exposed to toxic drugs. For $\operatorname{lmrCD}$, the drug-induced expression levels were lower than those observed in the deregulated strain that lacked the $\operatorname{lm} r R$ gene, indicating that the drug-induced derepression is not maximized in such cells.

LmrR binds to two regions in the $\operatorname{lmr} C D$ operator sequence. Site I, comprising the -35 and -10 region leading to initiation at transcription start site $\mathrm{B}$, appears to be a high-affinity binding site for LmrR. Site II harbours an imperfect IR that is similar to the PadR consensus binding site, although the two half-sites are separated by 10 instead of 8 bp (Huillet et al., 2006). EMSA data suggested that the palindromic sequence on its own is only weakly recognized by LmrR (Supplementary Fig. S1), and that the binding of LmrR to the entire control region of the $\operatorname{lmr} C D$ genes results in one dominant species of DNA-protein complex. In-gel footprinting analysis supported the notion that in this complex, both site I and site II are protected by LmrR. Visualization of these protein-DNA complexes by AFM revealed a significant DNA bending, with two protein 'blobs' present on the DNA, wherein each 'blob' likely corresponds to one LmrR dimer. Taken together, these results suggest that site I and site II are each bound by an LmrR dimer in a highly cooperative manner, since it was not possible to detect a complex with only the higheraffinity site I bound. On the other hand, an EMSA with LmrR binding to the control region of its own gene revealed the formation of several distinct complexes. In-gel footprinting revealed that in this control region, multiple copies of the LmrR protein bind and that this is a sequential event, nucleated by binding to a site just upstream of the -35 box and extending further downstream, overlapping the promoter and transcription initiation site, and spreading into the $\operatorname{lm} r R$ ORF. A PadR-like imperfect IR is located in the middle of this large protected zone, and might be recognized by LmrR. This binding seems to involve a cooperative mechanism in which protein-protein interactions between adjacently bound LmrR dimers and DNA conformational changes play an important role. It yields a higher-order multimeric LmrR-DNA complex in which the DNA is condensed, looped or even wrapped around the protein, as suggested by the AFM observations. Earlier observations describing the cooperative binding of two dimers of the $\lambda$ repressor to 


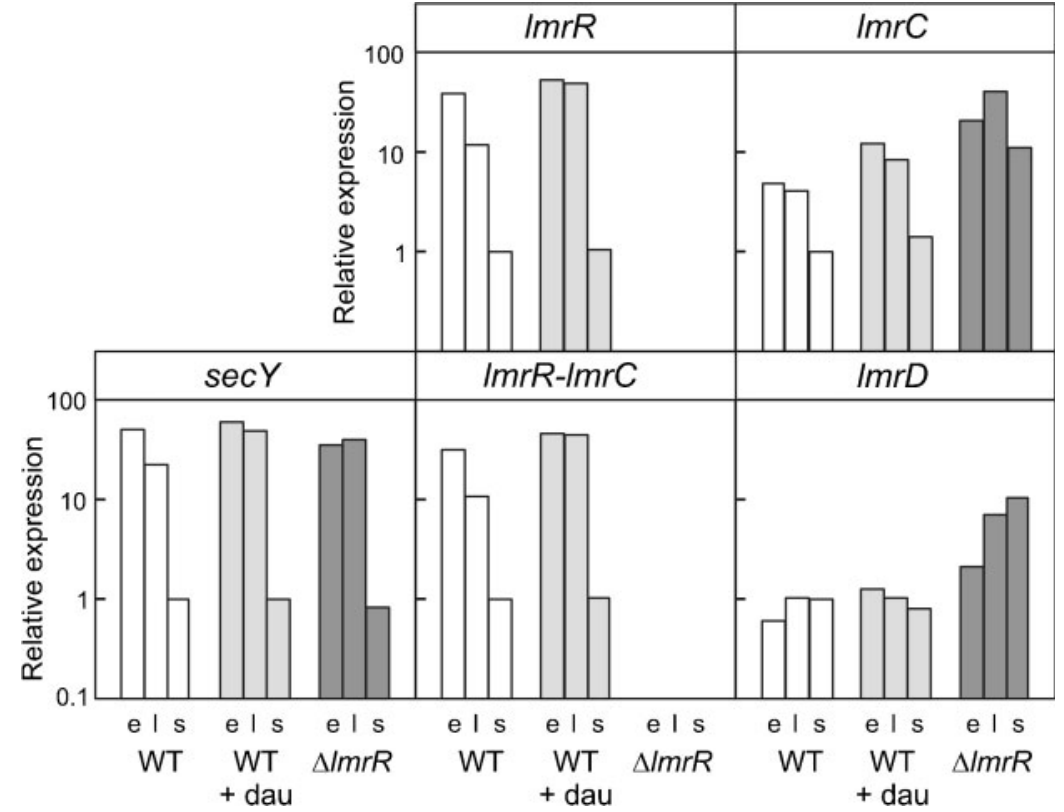

Fig. 6. qPCR expression analysis of $\operatorname{lmr} C D$, $I m r R$ and the intergenic region that separates the ImrR and ImrC genes in L. lactis NZ9000 (WT; white bars) cells grown to different growth stages in the absence and presence of daunomycin (dau; light-grey bars). L. lactis $\mathrm{NZ9000}(\Delta / m r R)$ cells (dark-grey bars) were included as a control. Expression levels were related to those of elongation factor Tu (tufA), and normalized for each gene to the expression in the stationary phase of $L$. lactis NZ9000 cells in the absence of daunomycin. $\sec Y$ was used as an additional housekeeping gene. The efficiency of amplification reactions was determined by running a standard curve with serial dilutions of cDNA. PCR efficiencies were similar for the various primer sets and were above $95 \%$. Growth phases: e, early exponential; I, late exponential; s, stationary. different and adjacent operator sites in the same DNA molecule have shown that this is mediated by the interactions between the carboxyl domains of the repressor molecules, which encourage the DNA to twist and bend due to its flexibility (Hochschild \& Ptashne, 1986). Moreover, the binding of the repressor to a strong binding site will enhance the binding affinity of a weaker site, thus promoting cooperative binding between repressor molecules as described above. The same mechanism may apply for the binding of LmrR to the two different sites in the $\operatorname{lm} r C D$ operator region. Overall, our data suggest that the mechanisms by which LmrR binds to the control regions of the $\operatorname{lm} r C D$ and $l m r R$ genes are different, with binding to $\mathrm{p} / \mathrm{o}$ $\operatorname{lm} r R$ occurring in a tighter fashion and with a higher binding affinity.

Based on our new insights, the following two-step mechanism of $\operatorname{lmrCD}$ regulation is envisaged (Fig. 7). Binding of two LmrR dimers to the $\operatorname{lm} r C D$ promoter region will result in a repression of $\operatorname{lmr} C D$ expression. Simultaneously, extensive binding of multiple LmrR dimers to the $\operatorname{lmrR}$ control region leads to a strong autorepression and repression of the $\operatorname{lmr} C D$ expression from the long transcript. When cells are challenged with toxic compounds, the drugs enter the cell and bind to LmrR. At first, this likely only causes a reduced binding of LmrR to the $\operatorname{lm} r C D$ operator binding sites. Consequently, there is a derepression of $\operatorname{lmr} C D$ transcription. At higher drug concentrations, the repression at the $\operatorname{lm} R$ operator site might also be relieved, since this is a higher-affinity binding involving more LmrR dimers that interact tightly with each other and with the strongly deformed DNA. This derepression yields a polycistronic messenger containing the information for the regulator and for the transporter, resulting in an even higher production of LmrCD.
Therefore, LmrR-mediated regulation of $\operatorname{lmr} C D$ expression is exerted from two different locations and by different mechanisms. Meanwhile, LmrR is also involved in an autorepression that is modulated by drugs. Only upon release of LmrR from the $l m r R$ operator site (at high intracellular drug concentrations) is additional LmrR regulatory protein produced. These additional regulatory protein molecules may ensure a fast response to re-repress $\operatorname{lm} r R$ and $\operatorname{lm} r C D$ expression, as most LmrR dimers are already saturated with the drug effector molecule. Newly synthesized LmrCD will insert into the membrane and mediate the export of the drugs from the cell. Due to the decreased cellular drug levels, LmrR will return to its apo form and reassociate first with $\mathrm{p} / \mathrm{o} \operatorname{lm} r R$ and then with the $\operatorname{lm} r C D$ operator site and again inhibit expression. This drugdependent regulatory phenomenon results in a fine-tuned demand-dependent expression of the LmrCD transporter.

In the previously studied MDR strains, the $\operatorname{lm} r R$ gene harbours mutation(s) that lead to the production of nonfunctional LmrR variants that are unable to repress the expression of either $\operatorname{lmrR}$ or $\operatorname{lmr} C D$ (Agustiandari et al., 2008). This causes not only the upregulation of $l m r C D$ but also increased levels of the $\operatorname{lm} r R$ transcript. Strikingly, microarray analysis of all four drug-resistant strains of $L$. lactis demonstrated that $\operatorname{lmrR}$ is significantly and more strongly (mean 9.4-fold) upregulated than $\operatorname{lmrCD}$ (mean 6.7-fold) (Lubelski et al., 2006), consistent with the notion that LmrR binds the $\operatorname{lmrR}$ promoter region more strongly than the $\operatorname{lmr} C D$ promoter region. Consequently, expression of $\operatorname{lm} r R$ is controlled by a well-tuned and damped feedback autoregulatory loop. This tightly controlled $\operatorname{lmr} R$ expression may serve to ensure a highly sensitive drugsensing regulatory mechanism of $\operatorname{lmr} C D$ expression. High cellular levels of LmrR would render this mechanism less 


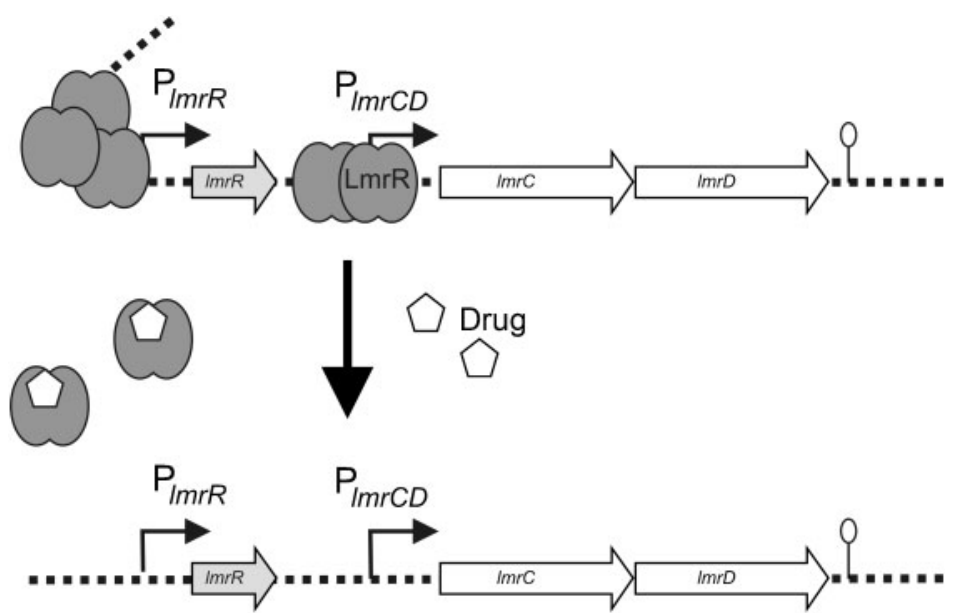

mRNA
Fig. 7. Schematic representation of the regulation of $I m r R$ and $I m r C D$ expression by $\mathrm{LmrR}$ in L. lactis. In wild-type cells growing in drug-free medium, LmrR binds and represses the transcription of both the $I m r C D$ gene and the $I m r R$ gene. Binding to the $I m r R$ operator sequences involves cooperative binding of multiple copies of the LmrR dimer, while LmrR binds as two dimers to the $\operatorname{ImrCD}$ operator sequences. When cells are challenged with a drug, the LmrR dimer binds a drug molecule and this causes the release of the LmrR-drug complex from the ImrCD and ImrR operator sequences, allowing the initiation of transcription with the formation of a polycistronic mRNA that supports the translation of both the ImrR gene and the $I m r C D$ gene, as well as mRNAs harbouring the $\operatorname{mrCD}$ genes only. sensitive to drugs, as increased intracellular drug concentrations would be needed to achieve derepression of $\operatorname{lmrCD}$ expression. In contrast, direct transcription from the $\operatorname{lm} r C D$ operator sites is likely more responsive to drugs because of a less extensive LmrR-binding mechanism. Since $\operatorname{lm} r R$ and $\operatorname{lm} r C D$ are at least partially co-transcribed, expression of high levels of LmrCD is prevented, as the newly synthesized LmrR will readily repress further transcription. This will for instance minimize the risk that hydrophobic metabolites important to the cell are lost due to uncontrolled and unwanted secretion. Indeed, in the L. lactis $\mathrm{NZ9000}(\Delta \mathrm{lm} r R)$ strain, higher $\operatorname{lmrCD}$ transcript levels are observed than in wild-type cells challenged with drugs. Future studies are required to determine the exact stoichiometry of LmrR binding to the various operator sequences and to unravel the molecular details of the LmrR-imposed control of promoter activity (inhibition of closed complex formation, isomerization, promoter clearance).

\section{ACKNOWLEDGEMENTS}

We thank Andy-Mark Thunnissen for discussion and valuable suggestions. We thank Structural Biology Brussels (Vrije Universiteit Brussel) for the use of their AFM equipment. E.P. is a postdoctoral fellow of Fonds Wetenschappelijk Onderzoek (FWO)-Vlaanderen.

\section{REFERENCES}

Abramoff, M. D., Magelhaes, P. J. \& Ram, S. J. (2004). Image processing with ImageJ. Biophotonics International 11, 36-42.

Agustiandari, H., Lubelski, J., van den Berg van Saparoea, H. B., Kuipers, O. P. \& Driessen, A. J. M. (2008). LmrR is a transcriptional repressor of expression of the multidrug ABC transporter LmrCD in Lactococcus lactis. J Bacteriol 190, 759-763.

Alekshun, M. N. \& Levy, S. B. (1997). Regulation of chromosomally mediated multiple antibiotic resistance: the mar regulon. Antimicrob Agents Chemother 41, 2067-2075.
Bolhuis, H., Molenaar, D., Poelarends, G., van Veen, H. W., Poolman, B., Driessen, A. J. M. \& Konings, W. N. (1994). Proton motive force-driven and ATP-dependent drug extrusion systems in multidrug-resistant Lactococcus lactis. J Bacteriol 176, 6957-6964.

Chopra, I. \& Roberts, M. (2001). Tetracycline antibiotics: mode of action, applications, molecular biology, and epidemiology of bacterial resistance. Microbiol Mol Biol Rev 65, 232-260.

Eckert, B. \& Beck, C. F. (1989). Overproduction of transposon Tn10encoded tetracycline resistance protein results in cell death and loss of membrane potential. J Bacteriol 171, 3557-3559.

Enoru-Eta, J., Gigot, D., Thia-Toong, T. L., Glansdorff, N. \& Charlier, D. (2000). Purification and characterization of Sa-lrp, a DNA-binding protein from the extreme thermoacidophilic archaeon Sulfolobus acidocaldarius homologous to the bacterial global transcriptional regulator Lrp. J Bacteriol 182, 3661-3672.

Enoru-Eta, J., Gigot, D., Glansdorff, N. \& Charlier, D. (2002). High resolution contact probing of the Lrp-like DNA-binding protein SsLrp from the hyperthermoacidophilic crenarchaeote Sulfolobus solfataricus P2. Mol Microbiol 45, 1541-1555.

Friedrich, U. \& Lenke, J. (2006). Improved enumeration of lactic acid bacteria in mesophilic dairy starter cultures by using multiplex quantitative real-time PCR and flow cytometry-fluorescence in situ hybridization. Appl Environ Microbiol 72, 4163-4171.

Gasson, M. J., Kitamura, Y., McLauchlan, W. R., Narbad, A., Parr, A. J., Parsons, E. L., Payne, J., Rhodes, M. J. \& Walton, N. J. (1998). Metabolism of ferulic acid to vanillin. A bacterial gene of the enoyl-SCoA hydratase/isomerase superfamily encodes an enzyme for the hydration and cleavage of a hydroxycinnamic acid SCoA thioester. J Biol Chem 273, 4163-4170.

Grkovic, S., Brown, M. H. \& Skurray, R. A. (2002). Regulation of bacterial drug export systems. Microbiol Mol Biol Rev 66, 671701.

Gury, J., Barthelmebs, L., Tran, N. P., Diviès, C. \& Cavin, J. F. (2004). Cloning, deletion, and characterization of PadR, the transcriptional repressor of the phenolic acid decarboxylase-encoding padA gene of Lactobacillus plantarum. Appl Environ Microbiol 70, 2146-2153.

Hickman, R. K., McMurry, L. M. \& Levy, S. B. (1990). Overproduction and purification of the Tn10-specified inner membrane tetracycline resistance protein Tet using fusions to $\beta$-galactosidase. Mol Microbiol 4, 1241-1251. 
Hochschild, A. \& Ptashne, M. (1986). Cooperative binding of $\lambda$ repressors to sites separated by integral turns of the DNA helix. Cell 44, 681-687.

Hsieh, P. C., Siegel, S. A., Rogers, B., Davis, D. \& Lewis, K. (1998). Bacteria lacking a multidrug pump: a sensitive tool for drug discovery. Proc Natl Acad Sci U S A 95, 6602-6606.

Huillet, E., Velge, P., Vallaeys, T. \& Pardon, P. (2006). LadR, a new PadR-related transcriptional regulator from Listeria monocytogenes, negatively regulates the expression of the multidrug efflux pump MdrL. FEMS Microbiol Lett 254, 87-94.

Lubelski, J., Mazurkiewicz, P., van Merkerk, R., Konings, W. N. \& Driessen, A. J. M. (2004). $y d a G$ and $y d b A$ of Lactococcus lactis encode a heterodimeric ATP-binding cassette-type multidrug transporter. J Biol Chem 279, 34449-34455.

Lubelski, J., de Jong, A., van Merkerk, R., Agustiandari, H., Kuipers, O. P., Kok, J. \& Driessen, A. J. M. (2006). LmrCD is a major multidrug resistance transporter in Lactococcus lactis. Mol Microbiol 61, 771-781.

Ma, D., Alberti, M., Lynch, C., Nikaido, H. \& Hearst, J. E. (1996). The local repressor AcrR plays a modulating role in the regulation of acrAB genes of Escherichia coli by global stress signals. Mol Microbiol 19, 101-112.

Madoori, P. K., Agustiandari, H., Driessen, A. J. M. \& Thunnissen, A. M. (2009). Structure of the transcriptional regulator LmrR and its mechanism of multidrug recognition. EMBO J 28, 156-166.

Maxam, A. M. \& Gilbert, W. (1980). Sequencing end-labeled DNA with base-specific chemical cleavages. Methods Enzymol 65, 499-560.

Mazurkiewicz, P., Driessen, A. J. M. \& Konings, W. N. (2004). Energetics of wild-type and mutant multidrug resistance secondary transporter LmrP of Lactococcus lactis. Biochim Biophys Acta 1658, 252-261.

Minh, P. N. L., Devroede, N., Massant, J., Maes, D. \& Charlier, D. (2009). Insights into the architecture and stoichiometry of Escherichia coli $\mathrm{PepA}^{\star} \mathrm{DNA}$ complexes involved in transcriptional control and site-specific DNA recombination by atomic force microscopy. Nucleic Acids Res 37, 1463-1476.

Musso, R. E., Di Lauro, R., Adhya, S. \& de Crombrugghe, B. (1977). Dual control for transcription of the galactose operon by cyclic AMP and its receptor protein at two interspersed promoters. Cell 12, 847854.

Neyfakh, A. A., Bidnenko, V. E. \& Chen, L. B. (1991). Efflux-mediated multidrug resistance in Bacillus subtilis: similarities and dissimilarities with the mammalian system. Proc Natl Acad Sci U S A 88, 4781-4785.

Neyfakh, A. A., Borsch, C. M. \& Kaatz, G. W. (1993). Fluoroquinolone resistance protein NorA of Staphylococcus aureus is a multidrug efflux transporter. Antimicrob Agents Chemother 37, 128-129.
Ng, E. Y., Trucksis, M. \& Hooper, D. C. (1994). Quinolone resistance mediated by norA: physiologic characterization and relationship to $f l q B$, a quinolone resistance locus on the Staphylococcus aureus chromosome. Antimicrob Agents Chemother 38, 1345-1355.

Overhage, J., Priefert, H. \& Steinbüchel, A. (1999). Biochemical and genetic analyses of ferulic acid catabolism in Pseudomonas sp. strain HR199. Appl Environ Microbiol 65, 4837-4847.

Paulsen, I. T., Nguyen, L., Sliwinski, M. K., Rabus, R. \& Saier, M. H., Jr (2000). Microbial genome analyses: comparative transport capabilities in eighteen prokaryotes. J Mol Biol 301, 75-100.

Peeters, E., Thia-Toong, T. L., Gigot, D., Maes, D. \& Charlier, D. (2004). Ss-LrpB, a novel Lrp-like regulator of Sulfolobus solfataricus P2, binds cooperatively to three conserved targets in its own control region. Mol Microbiol 54, 321-336.

Peeters, E., Willaert, R., Maes, D. \& Charlier, D. (2006). Ss-LrpB from Sulfolobus solfataricus condenses about 100 base pairs of its own operator DNA into globular nucleoprotein complexes. J Biol Chem 281, 11721-11728.

Rahmati, S., Yang, S., Davidson, A. L. \& Zechiedrich, E. L. (2002). Control of the AcrAB multidrug efflux pump by quorum-sensing regulator SdiA. Mol Microbiol 43, 677-685.

Rivetti, C., Guthold, M. \& Bustamante, C. (1996). Scanning force microscopy of DNA deposited onto mica: equilibration versus kinetic trapping studied by statistical polymer chain analysis. J Mol Biol 264, 919-932.

Saier, M. H., Jr, Paulsen, I. T., Sliwinski, M. K., Pao, S. S., Skurray, R. A. \& Nikaido, H. (1998). Evolutionary origins of multidrug and drug-specific efflux pumps in bacteria. FASEB J 12, 265-274.

Schumacher, M. A. \& Brennan, R. G. (2003). Deciphering the molecular basis of multidrug recognition: crystal structures of the Staphylococcus aureus multidrug binding transcription regulator QacR. Res Microbiol 154, 69-77.

Segura, A., Bünz, P. V., D’Argenio, D. A. \& Ornston, L. N. (1999). Genetic analysis of a chromosomal region containing vanA and vanB, genes required for conversion of either ferulate or vanillate to protocatechuate in Acinetobacter. J Bacteriol 181, 3494-3504.

Tennent, J. M., Lyon, B. R., Gillespie, M. T., May, J. W. \& Skurray, R. A. (1985). Cloning and expression of Staphylococcus aureus plasmidmediated quaternary ammonium resistance in Escherichia coli. Antimicrob Agents Chemother 27, 79-83.

Zaidi, A. H., Bakkes, P. J., Lubelski, J., Agustiandari, H., Kuipers, O. P. \& Driessen, A. J. M. (2008). The ABC-type multidrug resistance transporter LmrCD is responsible for an extrusion-based mechanism of bile acid resistance in Lactococcus lactis. J Bacteriol 190, 7357-7366.

Edited by: A. R. Walmsley 